\section{Fumigating 'Crimson Seedless' Table Grapes with $(E)$-2-Hexenal Reduces Mold during Long-term Postharvest Storage}

\author{
Douglas D. Archbold ${ }^{1}$, Thomas R. Hamilton-Kemp, Ann M. Clements, \\ and Randy W. Collins \\ Department of Horticulture and Landscape Architecture, University of \\ Kentucky, Lexington, KY 40546-0091
}

Additional index words. leaf aldehyde, lipoxygenase, Vitis vinifera, Botrytis cinerea

\begin{abstract}
Seedless table grapes (Vitis vinifera $\mathrm{L}$.) cv. Crimson Seedless were exposed to $(E)$ 2-hexenal vapor during cold storage to determine its potential as a fumigant for long-term control of postharvest mold. Fruit were fumigated with 0.86 or $1.71 \mathrm{mmol}(100 \mathrm{or} 200 \mu \mathrm{L}$ neat compound, respectively) $(E)$-2-hexenal per 1.1-L container for 2 weeks during $2{ }^{\circ} \mathrm{C}$ storage. Containers were moved to $20^{\circ} \mathrm{C}$ storage after 4,8 , and 12 weeks for determination of mold incidence and berry quality over 12 days. The headspace concentration of $(E)-2-$ hexenal, measured by gas chromatography, reached a maximum of 2.5 and $4.2 \mu \mathrm{mol} \cdot \mathrm{L}^{-1}$ for 0.86 and $1.71 \mathrm{mmol}$ per container, respectively, after 1 day and declined to $\left\langle 1 \mu \mathrm{mol} \cdot \mathrm{L}^{-1}\right.$ for both treatments by 14 days. Upon removal from cold storage at 4,8 , and 12 weeks, the incidence of mold was significantly lower for $(E)$-2-hexenal-treated fruit. Control of mold by $(E)$-2-hexenal fumigation persisted through 12 days of $20^{\circ} \mathrm{C}$ storage, even though mold generally increased in all treatments. The two levels of $(E)$-2-hexenal were similar in their suppression of mold. Fumigation did not affect $\mathrm{O}_{2}$ or $\mathrm{CO}_{2}$ concentrations within the containers, nor were fruit firmness or soluble solids content affected. Postharvest fumigation of seedless table grapes with the natural volatile compound $(E)$-2-hexenal shows promise for control of mold.
\end{abstract}

Table grapes may be cold stored for as long as 5 months prior to marketing, but postharvest decay organisms, such as gray mold (Botrytis cinerea Pers.), can become a significant problem limiting prolonged storage (Nelson, 1991). Repeated fumigation with $\mathrm{SO}_{2}$ is commonly used to control postharvest molds on grapes. The technique has been refined to minimize sulfite residues left on the fruit (Luvisi et al., 1990, 1991), which is of concern because of allergic responses to sulfite residues. However, as application rates are lowered, control of postharvest mold is reduced (Smilanick and Henson, 1992; Smilanick et al., 1990).

Alternative fumigants have shown potential for postharvest decay control on grapes. Hydrogen peroxide vapor effectively reduces mold on $B$. cinerea-inoculated table grapes without adverse effects on berry quality (Forney et al., 1991; Rij and Forney, 1995).

Received for publication 29 June 1998. Accepted for publication 5 Jan. 1999. The investigation reported in this Paper (No. 98-11-89) is in connection with a project of the Kentucky Agricultural Experiment Station and is published with the approval of the director. The authors thank Sun World International, Bakersfield, Calif., and Corrin Produce Sales, Reedley, Calif., for providing the grapes for the research. The cost of publishing this paper was defrayed in part by the payment of page charges. Under postal regulations, this paper therefore must be hereby marked advertisement solely to indicate this fact.

${ }^{1}$ To whom correspondence should be addressed.
Acetic acid vapor can also reduce mold to negligible levels on grapes (Moyls et al., 1996; Sholberg and Gaunce, 1995). Recently, we demonstrated that a group of natural volatile products from plant tissues effectively suppressed mold development on grapes during short-term storage (Archbold et al., 1997). We have focused on one compound of this group, (E)-2-hexenal, because of its ubiquity (Hatanaka, 1993) and its antifungal activity against B. cinerea (Falliket al., 1998; HamiltonKemp et al., 1992). Other related products of the lipoxygenase-lyase pathway, such as hexanal and (Z)-3-hexenal, can also suppress mold development on fruit during postharvest storage (Archbold et al., 1997; Caccioni et al., 1995; Song et al., 1996; Vaughn et al., 1993).

The objective of this work was to determine the effect of fumigation with $(E)$-2hexenal on incidence of mold and berry quality of seedless table grapes during long-term storage.

\section{Materials and Methods}

'Crimson Seedless' grapes were harvested in California and shipped overnight to the Univ. of Kentucky on two occasions. The grapes were neither precooled nor fumigated with $\mathrm{SO}_{2}$ prior to shipment. Upon arrival, the grapes were immediately used in the experiments.

Clusters of fruit $(\approx 150 \mathrm{~g})$ that fit into 150 $\mathrm{mL}$ plastic clamshell containers were cut from larger clusters. The clusters were selected on the basis of uniform size, color, firmness, and freedom from evident defects or diseases. The effect of both vapor phase concentration of (E)-2-hexenal and duration of exposure to the vapor were tested in this study. Liquid $(E)$-2hexenal at 0 (control), 0.86 , or $1.71 \mathrm{mmol}$ ( 100 or $200 \mu \mathrm{L}$, respectively) of neat compound in a $10-\mathrm{mL}$ glass vial was placed within each container. Containers were loosely overwrapped, hermetically sealed in low-density polyethylene film (Type OF50, film thickness $0.0021 \mu \mathrm{m}$; Respire Films, West Conshohocken, Pa.) for a total volume of $1.1 \mathrm{~L}$, and stored at $2{ }^{\circ} \mathrm{C}$. The effect of duration of $(E)-2-$ hexenal treatment was evaluated by removing the vial of $(E)$-2-hexenal from a subset of containers at 4 or 8 weeks. Thus, after 12 weeks of cold storage, fruit had been exposed to $0,0.86$, or $1.71 \mathrm{mmol}(E)$-2-hexenal for the initial 4,8 , or 12 weeks.

The headspace vapor concentration of $(E)$ 2-hexenal within three overwrapped containers of each of the treatments was sampled through the film at $1,3,7$, and $14 \mathrm{~d}$ of storage, as previously described (Fallik et al., 1998).

At 4,8 , and 12 weeks of cold storage, the $\mathrm{O}_{2}$ and $\mathrm{CO}_{2}$ concentrations within the sealed bags were measured. A 5-mL aliquot of the atmosphere was collected using a 5-mL syringe, the hole was resealed with tape, and the sample was measured with an oxygen/carbon dioxide analyzer (model ZR 892 HS; Illinois Instruments, McHenry, Ill.).

To fumigate fruit for different durations, vials of $(E)$-2-hexenal were removed from a subset of clamshell containers at 4 and 8 weeks, before their cold-storage period had ended. Because opening the film-wrapped containers restored the $\mathrm{O}_{2}$ and $\mathrm{CO}_{2}$ to ambient levels, all packages were opened and clamshells were briefly removed at each interval. The clamshells were returned to the same film bag, which was resealed, and the packages were returned to cold storage.

After 4,8 , and 12 weeks of $2{ }^{\circ} \mathrm{C}$ storage, five containers of each treatment were removed from storage. After measuring the $\mathrm{O}_{2}$ and $\mathrm{CO}_{2}$ levels, the film and remaining vials were removed, and the containers were placed at $20{ }^{\circ} \mathrm{C}$. Mold incidence was evaluated on three containers for each treatment every other day through $12 \mathrm{~d}$. The relative number of infected fruit per container was estimated and assigned to one of five groups: no mold $=1$; $10 \%$ or less of the berries with mold $=2 ; 11 \%$ to $30 \%$ of the berries with mold $=3 ; 31 \%$ to $70 \%$ of the berries with mold $=4$; and $>70 \%$ of the fruit with mold $=5$. Three experienced evaluators independently rated each container. The mean rating of each container on each evaluation date was used for statistical analysis.

For analysis of weight loss during the experiment, all containers were weighed at the start, upon removal from cold storage, and after 4,7 , and $12 \mathrm{~d}$ of $20^{\circ} \mathrm{C}$ storage. The percentage of weight loss at each time was calculated for each container.

Berries were sampled for quality analyses at the start of the experiments, upon removal from cold storage, and after $4 \mathrm{~d}$ of $20{ }^{\circ} \mathrm{C}$ 
storage. Ten berries were randomly selected at the start of the experiment and from each of the two remaining nonrated containers stored at $20^{\circ} \mathrm{C}$. Berry firmness was measured using a force gauge (model DFM 10; John Chatillon and Sons, Greensboro, N.C.) mounted on a model LTC test stand (John Chatillon and Sons) and equipped with a 13-mm-wide flat head. The force required for a $2-\mathrm{mm}$ compression of the berry lying horizontally on the stage with slow manual advancement of the head was recorded. Berry total soluble solids (TSS) content was then measured using a refractometer (AO Scientific Instruments, Keene, N.H.).

Two shipments of grapes from separate commercial companies were used in this work. Five containers per $(E)$-2-hexenal level by duration of treatment for each removal date were set up with each shipment. Three were used for evaluation of mold incidence and weight loss and the remaining two were used for sampling berries for quality analyses. Mean compression and TSS values for each container were derived from the sampled berries.
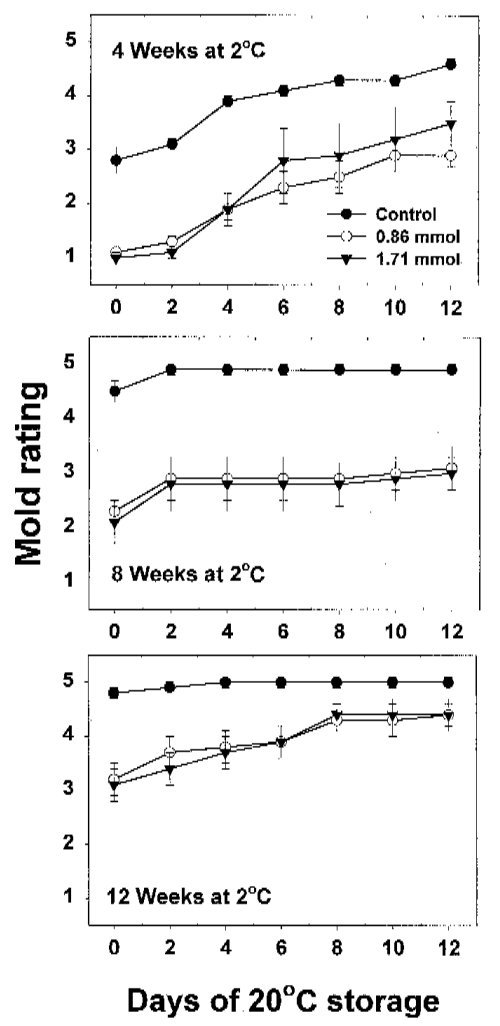

Fig. 1. Effect of (E)-2-hexenal fumigation on incidence of mold in 'Crimson Seedless' grapes during $12 \mathrm{~d}$ of $20^{\circ} \mathrm{C}$ storage after 4,8 , or 12 weeks. Each film-wrapped clamshell container of grapes contained no (control), $0.86 \mathrm{mmol}$ $(100 \mu \mathrm{L})$, or $1.71 \mathrm{mmol}(200 \mu \mathrm{L})$ of $(E)-2-$ hexenal. Means \pm SE of 6,12 , or 18 replicate containers at 4,8 , and 12 weeks, respectively. Treatment means were significantly lower than control means, but not from one another, at $P \leq$ 0.05 on all days after 4,8 , and 12 weeks of $2{ }^{\circ} \mathrm{C}$ storage. Mold ratings are: no mold $=1 ; 10 \%$ or less of the berries with mold $=2 ; 11 \%$ to $30 \%$ of the berries with mold $=3 ; 31 \%$ to $70 \%$ of the berries with mold $=4$; and $>70 \%$ of the fruit with mold $=5$.
Data were blocked by shipment date and subjected to analysis of variance (ANOVA). Ratings data were found to have acceptable homogeneity of variance and normality (SigmaStat; SPSS, Chicago), so they were not transformed. The main effects of $(E)$-2-hexenal level, duration of treatment, and their interaction, as well as trends within each of the main effects, were determined by ANOVA (SAS Institute, Cary, N.C.). Only main effect means for $(E)$-2-hexenal levels are presented, because no other effects were significant.

\section{Results and Discussion}

Fumigation of 'Crimson Seedless' grapes with $(E)$-2-hexenal significantly reduced the incidence of mold as determined upon removal of the fruit from cold storage after 4, 8 , and 12 weeks (Figs. 1 and 2). The two levels of (E)-2-hexenal, 0.86 and $1.71 \mathrm{mmol}$, were equally effective. Mold developed on $(E)$-2hexenal-fumigated fruit during $20^{\circ} \mathrm{C}$ storage, but it remained significantly below control values through $12 \mathrm{~d}$ of shelf storage.

The headspace concentration of $(E)$-2hexenal was highest within $1 \mathrm{~d}$ of $2{ }^{\circ} \mathrm{C}$ storage (Fig. 3). It was also greater in containers with no fruit than in those containing fruit, indicating that the fruit absorbed the compound. Prior work indicated both a similar trend of headspace concentration over time and absorption of compound with treatment of a single berry (Archbold et al., 1997). The film used to overwrap the containers also probably absorbed (E)-2-hexenal, contributing to the decline in headspace concentration over time
(Sadler and Braddock, 1991). Headspace concentration of $(E)$-2-hexenal was greater with $1.71 \mathrm{mmol}$ in the container than with 0.86 mmol. By the end of 2 weeks of storage, the headspace concentrations in the two treatments had declined more than 3-fold from their levels at Day 1 . All bags were vented at 4-week intervals to prevent development of anaerobic conditions, and the headspace levels of $(E)$-2-hexenal were probably not subsequently re-established at levels near $1 \mu \mathrm{mol} \cdot \mathrm{L}^{-1}$. Subsequent attempts to measure headspace levels by GC analysis were prevented by interfering peaks, possibly due to release of plasticizers by the film.

Treatment with $(E)$-2-hexenal did not affect the $\mathrm{O}_{2}$ and $\mathrm{CO}_{2}$ levels in the sealed bags (data not shown). The $\mathrm{O}_{2}$ levels were $15.8 \% \pm$ $0.3 \%$ and $\mathrm{CO}_{2}$ levels were $5.1 \% \pm 0.1 \%$ after each 4-week interval of cold storage. Weight loss was also unaffected by $(E)$-2-hexenal treatment. Berry weight was $0.9 \% \pm 0.1 \%$ less on removal from cold storage than at the start, and loss increased with time at $20^{\circ} \mathrm{C}$, exceeding $5 \%$ after $4 \mathrm{~d}$ at $20^{\circ} \mathrm{C}$. Treatment with $(E)-2-$ hexenal also had no effect on berry firmness, which declined as percent weight loss increased. Berry TSS content was not affected by fumigation treatment or length of cold storage, averaging $19.4 \% \pm 0.1 \%$ overall, but increased $1.4 \% \pm 0.1 \%$ after $3 \mathrm{~d}$ of $20{ }^{\circ} \mathrm{C}$ storage, probably because of water loss by the berries. Overall, fumigation with $(E)$-2-hexenal had no adverse impact on these important berry quality traits.

Similar postharvest studies with strawberry (Fragaria $\times$ ananasssa Duch.) resulted in sig-

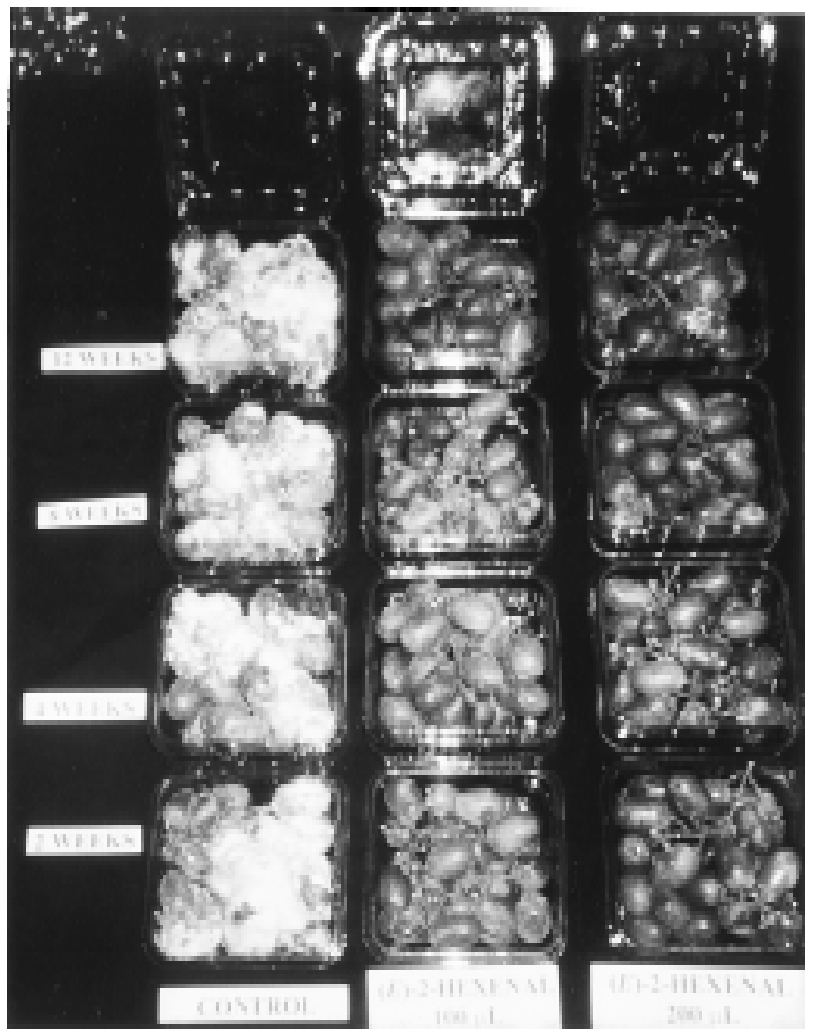

Fig. 2. The effect of fumigation with (E)-2-hexenal on mold in 'Crimson Seedless' grapes after 12 weeks of $4{ }^{\circ} \mathrm{C}$ storage. Each film-wrapped clamshell container of grapes contained no (control), $0.86 \mathrm{mmol}$ (100 $\mu \mathrm{L})$, or $1.71 \mathrm{mmol}(200 \mu \mathrm{L})$ of $(E)$-2-hexenal. 


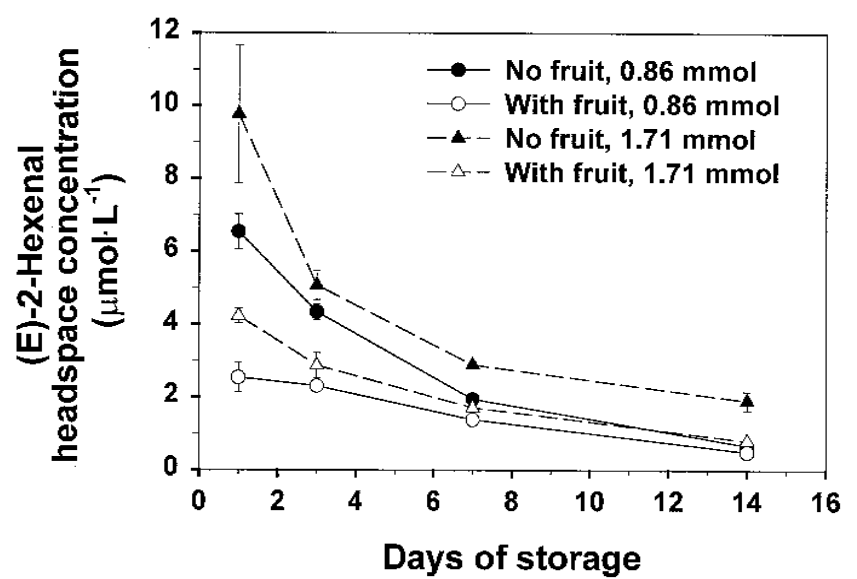

Fig. 3. Headspace concentration of (E)-2-hexenal in film-wrapped containers with or without 'Crimson Seedless' grapes during the first 2 weeks of fumigation with $0.86 \mathrm{mmol}(100 \mu \mathrm{L})$ or $1.71 \mathrm{mmol}(200 \mu \mathrm{L})$ of the compound. Each data point represents the mean $\pm \mathrm{SE}$ of three replicate containers.

nificant stimulation of mold development on that fruit (Fallik et al., 1998). It was estimated from headspace measurements that values of (E)-2-hexenal below $0.5 \mu \mathrm{mol} \cdot \mathrm{L}^{-1}$ led to stimulation of $B$. cinerea mycelial development in vitro, while values above it accompanied inhibition of mold. Headspace concentration of (E)-2-hexenal in containers of strawberry fruit, set up identically to those in the present study with $0.86 \mathrm{mmol}$ of compound, was 0.37 $\mu \mathrm{mol} \cdot \mathrm{L}^{-1}$ after $2 \mathrm{~d}$ of cold storage, too low for inhibition of mold and over 5-fold below those measured with grapes. As noted previously, strawberry has a significantly greater capacity for absorption and metabolism of $(E)$-2-hexenal than does grape (Archbold et al., 1997). Thus, a greater headspace concentration of $(E)$-2hexenal could be sustained with grapes than with strawberries, and mold was inhibited, in contrast to the results with strawberry. Although $B$. cinerea was the primary mold observed on control fruit, others such as Rhizopus and Penicillium were also noted, so $(E)-2$ hexenal probably suppressed all types present.

Introduction of an adequate amount of $(E)$ 2-hexenal into the table grape storage environment suppressed mold development. However, complete mold suppression was not achieved, and, since levels of the compound declined from the start, repeated introduction of $(E)$-2-hexenal may achieve better longterm suppression. Or, $(E)$-2-hexenal may be combined with $\mathrm{SO}_{2}$ to reduce fumigation frequency with the latter compound and thereby allay concerns over sulfite residues. The similarity in response to the two levels of $(E)$-2hexenal indicates that the higher level provided no advantage, but a minimum appropriate level might be below that provided by 0.86 mmol of compound. The ability of $(E)-2$ hexenal to suppress mold organisms and its presence as a part of the volatile profile of grapes, as well as of other fruits and vegetables (Nijssen et al., 1996), makes it and similar natural volatile products attractive potential fumigants.

\section{Literature Cited}

Archbold, D.D., T.R. Hamilton-Kemp, M.M. Barth, and B.E. Langlois. 1997. Identifying natural volatile compounds that control gray mold (Botrytis cinerea) during postharvest storage of strawberry, blackberry, and grape. J. Agr. Food Chem. 45:4032-4037.

Caccioni, D.R.L., G. Tonini, and M. Guizzardi. 1995. Antifungal activity of stone fruit aroma compounds against Monilinia laxa (Aderh. et Ruhl.) honey and Rhizopus stolonifer (Ehrenb.): In vivo trials. J. Plant Dis. and Protection 102:518-525.

Fallik, E., D.D. Archbold, T.R. Hamilton-Kemp, A.M. Clements, R.W. Collins, and M.E. Barth. 1998. (E)-2-hexenal can stimulate Botrytis cinerea growth in vitro and on strawberry fruit in vivo during storage. J. Amer. Soc. Hort. Sci. 123:875-881.

Forney, C.F., R.E. Rij, R. Denis-Arrue, and J.L. Smilanick. 1991. Vapor phase hydrogen perox- ide inhibits postharvest decay of table grapes. HortScience 26:1512-1514.

Hamilton-Kemp, T.R., C.T. McCracken Jr., J.H. Loughrin, R.A. Andersen, and D.F. Hildebrand. 1992. Effects of some natural volatile compounds on the pathogenic fungi Alternaria alternata and Botrytis cinerea. J. Chem. Ecol. 18:1083-1091.

Hatanaka, A. 1993. The biogeneration of green odour by green leaves. Phytochemistry $34: 1201-$ 1218.

Luvisi, D., J. Smilanick, J. Thompson, G. Mitchell, J. Knutson, H. Shorey, and D. Wood. 1990. 1989-1990 modernization of sulfur dioxide use on table grapes-Field research. California Table Grape Commission, Fresno.

Luvisi, D., J. Smilanick, J. Thompson, G. Mitchell, J. Knutson, H. Shorey, and D. Wood. 1991. 1990-1991 modernization of sulfur dioxide use on table grapes-Field research. California Table Grape Commission, Fresno.

Moyls, A.L., P.L. Sholberg, and A.P. Gaunce. 1996. Modified-atmosphere packaging of grapes and strawberries fumigated with acetic acid. HortScience 31:414-416.

Nelson, K.E. 1991. The grape, p. 125-167. In: N.A.M. Eskin (ed.). Quality and preservation of fruit. CRC Press, Boca Raton, Fla.

Nijssen, C.M., C.A. Vischer, H. Maarse, L.C. Willemsens, and M.H. Boehms. 1996. Volatile compounds in food. 7th ed. TNO Nutrition and Food Res. Inst., The Netherlands.

Rij, R.E. and C.F. Forney. 1995. Phytotoxicity of vapour phase hydrogen peroxide to Thompson Seedless grapes and Botrytis cinerea spores. Crop Protection 14:131-135.

Sadler, G.D. and R.J. Braddock. 1991. Absorption of citrus volatiles by low density polyethylene. J. Food Sci. 56:35-37.

Sholberg, P.L. and A.P. Gaunce. 1995. Fumigation of fruit with acetic acid to prevent postharvest decay. HortScience 30:1271-1275.

Smilanick, J.L., J.M. Harvey, P.L. Hartsell, D.J. Henson, C.M. Harris, D.C. Fouse, and M. Assemi. 1990. Influence of sulfur dioxide fumigant dose on residues and control of postharvest decay of grapes. Plant Dis. 74:418-421.

Smilanick, J.L. and D.J. Henson. 1992. Minimum gaseous sulphur dioxide concentrations and exposure periods to control Botrytis cinerea. Crop Protection 11:535-540.

Song, J., R. Leepipattanawit, W. Deng, and R.M. Beaudry. 1996. Hexanal vapor is a natural, metabolizable fungicide: Inhibition of fungal activity and enhancement of aroma biosynthesis in apple slices. J. Amer. Soc. Hort. Sci. 121:937942.

Vaughn, S.F., G.F. Spencer, and B.S. Shasha. 1993. Volatile compounds from raspberry and strawberry fruit inhibit postharvest decay fungi. J. Food Sci. 58:793-796. 